\title{
Forest conservation incentives and deforestation in the Ecuadorian Amazon
}

THEMATIC SECTION

Forest Ecosystem Services

KELLY W. JONES ${ }^{1 *}$, MARGARET B. HOLLAND ${ }^{2}$, LISA NAUGHTON-TREVES ${ }^{3}$, MANUEL MORALES ${ }^{4}$, LUIS SUAREZ ${ }^{5}$ AND KAYLA KEENAN ${ }^{6}$

${ }^{I}$ Colorado State University - Human Dimensions of Natural Resources, 238 Forestry Building, Fort Collins, Colorado 80521, USA, ${ }^{2}$ University of Maryland, Baltimore County - Department of Geography $\mathbb{E}$

Environmental Systems, Baltimore, Maryland, USA, ${ }^{3}$ University of Wisconsin-Madison-Department of

Geography, Madison, Wisconsin, USA, ${ }^{4}$ Ecolex, Quito, Ecuador,${ }^{5}$ Conservation International Ecuador, Quito,

Ecuador and ${ }^{6}$ University of Maryland, Baltimore County - Instructional Systems Design Program, Baltimore, Maryland, USA

Date submitted: 13 October 2015; Date accepted: 15 June 2016; First published online 22 August 2016

\section{SUMMARY}

Forest conservation incentives are a popular approach to combatting tropical deforestation. Here we consider a case where direct economic incentives for forest conservation were offered to newly titled smallholders in a buffer zone of a protected area in the northeastern Ecuadorian Amazon. We used quasi-experimental impact evaluation methods to estimate changes in forest cover for 63 smallholders enrolled in Ecuador's Socio Bosque program compared to similar households that did not enroll. Focus group interviews in 15 communities provided insight into why landowners enrolled in the program and how land use is changing. The conservation incentives program reduced average annual deforestation by $0.4-0.5 \%$ between 2011 and 2013 for those enrolled, representing as much as a $70 \%$ reduction in deforestation attributable to Socio Bosque. Focus group interviews suggested that some landowners chose to 'invest' in conservation because the agricultural capacity of their land was limited and economic incentives provided an alternative livelihood strategy. Interviews, however, indicated limits to increasing enrollment rates under current conditions, due to lack of trust and liquidity constraints. Overall, a hybrid public-private governance approach can lead to larger conservation outcomes than restrictions alone.

Keymords: Cuyabeno Faunal Production Reserve, impact evaluation, matching, payments for ecosystem services, quasiexperimental, rewards for ecosystem services, Socio Bosque, tropical deforestation

\footnotetext{
*Correspondence: Kelly W. Jones e-mail: Kelly.Jones@ colostate.edu

Supplementary material can be found online at http://dx.doi. org/10.1017/S0376892916000308
}

\section{INTRODUCTION}

Direct incentives for forest conservation are a popular approach to combatting tropical deforestation to protect and enhance environmental services. The exact design and goals of these approaches vary, with one commonly adopted label being payments for ecosystem services (PES) (Wunder 2015). In our study area, forest conservation incentives (FCIs) is the preferred term, reflecting voluntary agreements that landowners make to conserve forest in exchange for direct economic incentives; we adopt this term for the remainder of this paper. There are few studies that rigorously estimate the impact of FCIs on environmental outcomes (Samii et al. 2014). Impact evaluations of FCIs on forest cover in Latin America have found small, but in general, positive impacts on conservation (Scullion et al. 2011; Alix-Garcia et al. 2012).

FCIs are sometimes used as a complement to existing regulatory, or command-and-control, interventions in the tropics (Lambin et al. 2014). For example, the national law that enabled Costa Rica's pioneering PES program also prohibited clearing of mature forest (Daniels et al. 2010). In these cases, FCIs are expected to reinforce existing public regulations on forest use, especially where enforcement capacity is lacking. FCIs can also overlap with policies or institutions that encourage forest use, creating conflicting incentives. This type of overlap could occur when FCIs are placed in areas with existing agricultural subsidies.

We evaluated the ability of a FCI program to reduce deforestation on smallholder properties that recently acquired land titles in protected forest in the northeastern Ecuadorian Amazon. While government restrictions on deforestation are common in the tropics, enforcement of these regulations is limited (Lambin et al. 2014). Latin America has undergone a number of forest tenure reforms in the last decade (Pacheco et al. 2012), and secure tenure, usually in the form of formal land title, is a pre-requisite for most FCI programs (Wunder 2015). While the relationship between land tenure and deforestation is mixed (Robinson et al. 2014), when newly titled landowners have opportunities for commercial agriculture or extraction, or can sell the land 
to new users, deforestation may increase (Liscow 2013). Our study area represents a hybrid of direct and indirect governance approaches (public protected forest, new property laws, FCIs), some of which may encourage forest conservation and others that may not.

We used mixed methods to analyze the impact of Ecuador's national FCI program, Socio Bosque, on deforestation. Administered by the Ministry of the Environment (MAE), Socio Bosque was created in 2008 with the dual goals of protecting forests to provide important environmental services and poverty alleviation (de Koning et al. 2011). More than US\$55 million have been invested in contracts since the creation of the program, primarily financed through direct government budget allocation. In 2015, approximately $23 \%$ of funding was secured through the private sector and international donors, but Socio Bosque's goal is to increase this form of support to $50 \%$ of annual financing (Programa Socio Bosque, 2016). Landowner contracts are for 20 years and incentives are based on the amount of land enrolled, not its value. For example, the first 50 ha of land receive US\$30 ha ${ }^{-1}$ year $^{-1}$, the second 50 ha receive US $\$ 20 \mathrm{ha}^{-1}$ year $^{-1}$, and so forth. A condition for enrollment in the program is clear and uncontested land title. Enrolling in the program entails a commitment to not cut any trees. If this contract is violated, the landowner loses a payment. After three consecutive non-compliance violations the contract is terminated, and the landowner is required to pay back a percentage of what they received in the program. If termination occurs within the first five years, $100 \%$ payback is required. The same payback schedule applies to landowners that want to exit the program (MAE 2012).

To add to the empirical evidence of the impact of FCIs on reducing deforestation we used quasi-experimental evaluation methods to construct a valid counterfactual group and compare outcomes before and after the program starts to rule out rival explanations (Ferraro \& Hanauer 2014). Our evaluation of FCIs impact on forest cover is the first that we know of in the country to use counterfactual methods. Of course, knowing the quantitative impact of FCIs on forest cover may miss harder to assess information about how or why the program works - information that is imperative to sustaining the program over the long term. We conducted 15 community focus groups to understand why landowners participate in the FCI program and how land titling and FCIs have contributed to changes in landowner decision-making. This mixed method evaluation allowed us to quantify the impact of the FCI program on forest outcomes and provided insight on how the hybrid approaches to land governance in the region complement or contradict one another in achieving these outcomes.

\section{METHODS}

\section{Study area}

Our study focused on smallholders that live along the western boundary of Cuyabeno Faunal Production Reserve, in Sucumbíos Province, northeastern Ecuador
(Fig. 1). Originally created in 1979, the reserve protects a unique network of wetland and tropical forest ecosystems. Deforestation inside and around the reserve is an ongoing conservation issue (Holland et al. 2014). In 1994, 52000 ha around the western boundary of the reserve were taken out of Protected Area designation and placed under Patrimony Forest designation, a public land tenure category that allows limited forest use. This change was in response to settlement by roughly 4000 colonist families during the 1970 s and 1980s.

Colonist families banded together and formed 'precooperatives', an informal category of ownership intended to lead eventually to formal titles. Under this land tenure system, each household informally owned a parcel of land but did not hold government-issued title. In 2009, about 1000 households within 61 pre-cooperatives received individual formal land titles during a government-sponsored titling campaign. Because of the overlap with Patrimony Forest land, titles included a restriction that $70 \%$ of the property had to remain in forest conservation (MAE Ministerial Accord, No. 039, Article 7). However, government officials and legal experts acknowledge that enforcement of this environmental restriction is very limited (L. Borbor, personal communication 2015). Titled lands can be sold after five years but cannot be subdivided.

Sixty-three of the titled households, from 22 different pre-cooperatives, enrolled land in FCIs by 2010. Seventeen additional landowners enrolled in the program between 2010 and 2014; however, since we wanted to estimate the impact of the program on changes in deforestation, we limited our quantitative evaluation to the 63 landowners enrolled as of 2010 , representing about $7 \%$ of all newly titled land in the study area. Each landowner in the FCI program enrolled an average of $49 \mathrm{ha}$, or $77 \%$ of their parcel. At US\$30 $\mathrm{ha}^{-1}$ year $^{-1}$, this is an average annual payment of US $\$ 1470$; amount of annual payments ranged between US\$510 and US\$2970. A study in a neighbouring province estimates the average annual household income for colonist households at US\$3200 (Mejia et al. 2015). Livelihoods in the study area are a mix of subsistence agriculture, with some coffee, rice, cacao or livestock sold. Off-farm employment is an important source of income, but these jobs tend to be scarce and transitory.

\section{Impact evaluation}

We had property boundaries from a cadastral survey of all titled households in our study area; thus, our unit of analysis represented the household decision-making unit. Our outcome of interest was change in deforestation rates. We calculated deforestation rates for each titled property from a globally derived Landsat product for annual forest/nonforest land cover (Hansen et al. 2013). These data provided $30 \mathrm{~m}$ resolution data on percentage tree canopy cover; by aggregating up to the property boundary we constructed a continuous measure of annual forest cover change for each 


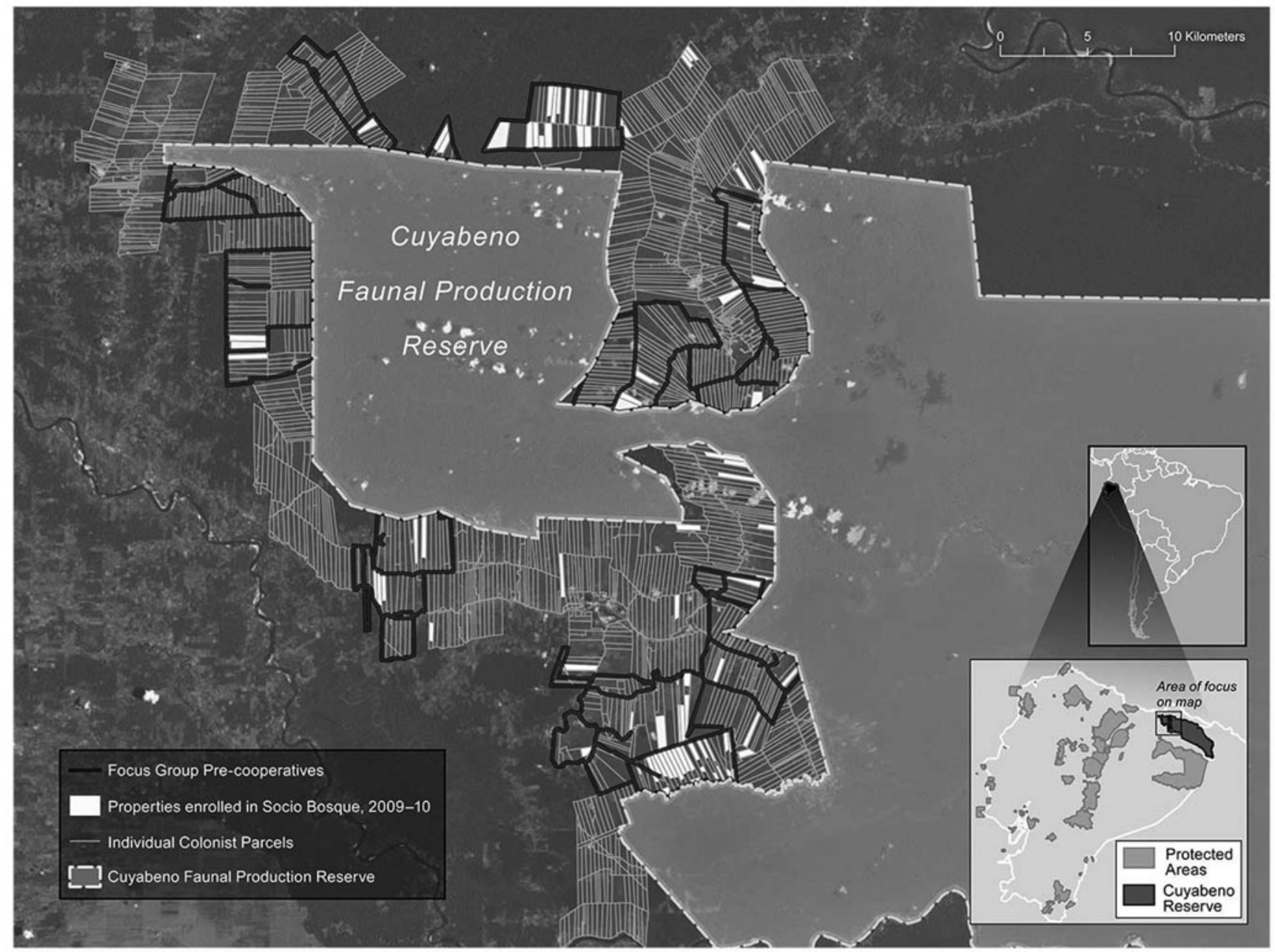

Figure 1 Study area: location of Cuyabeno Reserve, parcels enrolled and not enrolled in Socio Bosque, and pre-cooperatives where focus groups were conducted.

observation. We defined post-FCI outcomes as deforestation rates between 2011 and 2013. Pre-FCI deforestation rates are measured for the years 2004 to 2010.

To identify a valid control group for land enrolled in the FCI program, we used 'matching', which constructs a counterfactual group based on observable variables thought to influence receiving the program and the outcome of interest. First, we restricted eligible control units to the 22 pre-cooperatives where at least one household enrolled in a FCI as of 2010. This resulted in 450 titled properties not in the FCI program. Second, we used propensity score matching (PSM) to pair participant to non-participant households (Guo \& Fraser 2010). Participants were matched to the non-participant with the closest propensity score using one-to-one matching without replacement. To improve the quality of matches, a caliper equal to 0.25 the standard deviation of the estimated propensity score was used (Rubin 2006).

Based on previous evaluations of FCI programs and known drivers of tropical deforestation in the region, we matched on the following spatial variables: baseline deforestation rates, parcel size, and distance to primary roads, population centres, navigable rivers and oil wells (Alix-Garcia et al. 2012; Holland et al. 2014). Baseline deforestation rates were defined separately by three three-year periods to ensure results were not sensitive to chosen years: 2004-2006, 2005-2007 and 2006-2008. We checked covariate balance before and after matching using t-tests and normalized differences in means; matching should substantially improve the similarity of observable variables between the two groups. We also checked overlap of propensity score values. While we do not have household information to include in the match, a limitation of similar studies (Scullion et al. 2011; Alix-Garcia et al. 2012), these checks helped confirm that we found control observations similar to our FCI participants. The question of remaining bias is addressed in Appendix S1.

With the matched sample of participant and nonparticipant households, we estimated the impact of the FCI program on deforestation using linear fixed effects panel regression, which uses the temporal dynamics of the 
data (observing the two groups before and after the FCI program) along with cross-sectional variation in who received the program to construct the counterfactual outcomes. The advantage of this estimation method over matching combined with cross-sectional regression or t-tests is that in addition to observable variables it also controls for time-invariant unobservables that can bias program evaluation (Imbens \& Wooldridge 2009; Jones \& Lewis 2015).

In our study, where the unit of analysis was the parcel, the fixed effects method controlled for any time-invariant omitted parcel and household characteristics, since the same colonist household had user rights to these parcels before and after the FCI program started. Year fixed effects were also included and controlled for variations over time that affected all observations (e.g., national oil prices). The years of data used in the PSM equation to define baseline deforestation (e.g., 2004-2006) were not included in the fixed effects estimation. We accounted for serial and spatial correlation in the standard errors by estimating cluster robust standard errors, clustering on the pre-cooperative (Cameron \& Trivedi 2005). A more detailed description of our estimation approach is in Appendix S1, including a series of robustness checks to provide additional confidence in our estimation strategy and results.

\section{Focus group interviews}

We conducted 15 focus group interviews in June 2015; focus groups provide unique insight on sensitive topics and were appropriate for the exploratory nature of our questions (Morgan \& Krueger 1993). We utilized the community precooperative structure to arrange focus groups and stratified these groups by the number of households that received title (some households did not receive title), enrolled in FCIs and their proximity to the reserve boundary. Fifty-one of the 63 FCI households in our quantitative sample are located in these 15 pre-cooperatives. Focus group meetings were convened by a field assistant from the region, who hand-delivered formal invitations to the acting presidents of each pre-cooperative organization and invited participants to come to a central location. Attendance ranged between two and 19 persons, with a mean of seven persons, and across all the interviews we talked with 101 individuals. Focus groups lasted between one and two hours.

We used a semi-structured questionnaire (Appendix S2) to collect information from both participants and nonparticipants in FCIs on: their understanding of the goals and objectives of the program, motivating factors for participating or not in the program, and land uses on their properties. For participants in the FCI program we also asked about: the decision process by which lands were enrolled in the program, how land management practices had changed for enrolled land and how incentives were being used. IRB approval was obtained for the interview protocol and fluent Spanish speakers from our research team conducted the interviews.

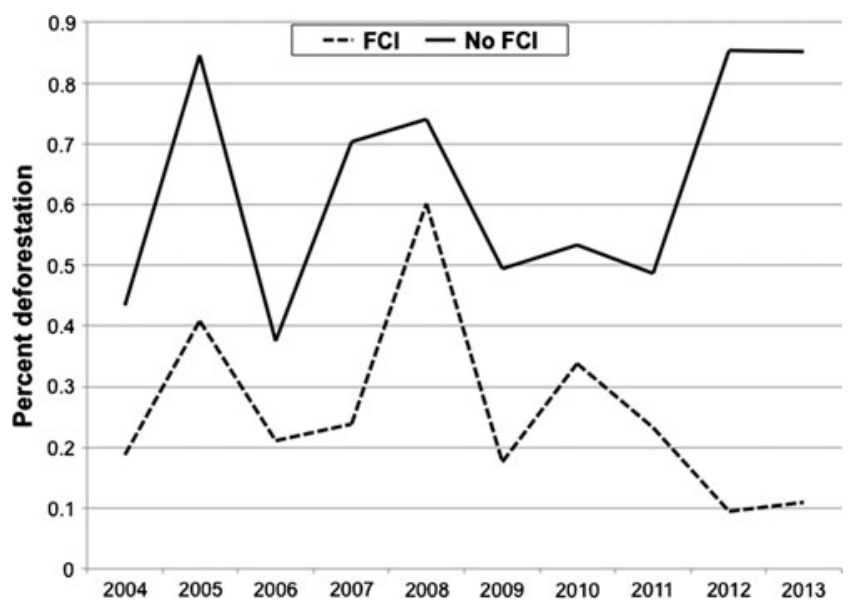

Figure 2 Deforestation rates of parcels enrolled and not enrolled in the FCI program before matching.

Data collected during focus groups were transcribed and translated into English, and reviewed for common themes and divergences across questions.

\section{RESULTS}

\section{Impact evaluation of changes in deforestation}

Mean annual deforestation rates were $<1 \%$ per year between 2004 and 2013 in our study area (Fig. 2). Deforestation rates on FCI lands prior to 2011 were an average $0.3 \%$ per year; after the program, they were $0.2 \%$ per year (Table 1 ). Mean deforestation for landowners who did not enroll in the program were $0.6 \%$ per year before 2011, and $0.7 \%$ per year for 2011-2013. Households that enrolled in FCIs had, on average, parcels of land that were larger than those not enrolled, and those parcels were farther from towns, roads, rivers and oil wells (all differences with $p<0.05$ or $<0.01$ except distance to river). After matching, no statistical differences remained. Normalized differences in means also improved after matching, with no differences greater than 0.25 . Overlap in propensity score values is high (Fig. 3). Graphs of trends in deforestation for the matched participants and non-participants indicated parallel trends prior to the FCI program, with clear divergences in deforestation occurring by 2012 (Appendix S3).

The FCI program reduced average annual deforestation by between 0.4 and $0.5 \%$, depending on how baseline deforestation is defined in matching (Table 2). This can be interpreted as a $0.4-0.5 \%$ reduction in the mean annual deforestation rate for 2011-2013 for lands enrolled in FCIs compared to similar lands that were not enrolled (all $p<0.05$ or $<0.01)$. Mean annual deforestation rates on matched control properties not enrolled in the FCI program in 2011-2013 were $0.6 \%$ (for 2004-2006 baseline), $0.6 \%$ (for 2005-2007 baseline) and $0.8 \%$ (for 2006-2008 baseline). We can use the deforestation rate on matched control observations to calculate 
Table 1 Summary statistics for FCI and non-FCI participants. Results after matching presented with baseline deforestation defined as 2004-2006; similar results were obtained when 2005-2007 and 2006-2008 were used in matching. ${ }^{* *} p<0.05 ;{ }^{* * *} p<0.01$.

\begin{tabular}{|c|c|c|c|c|c|c|}
\hline Variable & $\begin{array}{l}\text { FCI parcels before } \\
\text { match, Mean (SD) }\end{array}$ & $\begin{array}{l}\text { Non-FCI parcels } \\
\text { before match, } \\
\text { Mean (SD) }\end{array}$ & $\begin{array}{l}\text { T-test before } \\
\text { matching }\end{array}$ & $\begin{array}{l}\text { T-test after } \\
\text { matching }\end{array}$ & $\begin{array}{l}\text { Normalized } \\
\text { difference in } \\
\text { means before } \\
\text { matching }\end{array}$ & $\begin{array}{l}\text { Normalized } \\
\text { difference in } \\
\text { means after } \\
\text { matching } \\
\end{array}$ \\
\hline $\begin{array}{l}\text { Annual forest loss after FCI } \\
\text { program, 2011-2013 (\%) }\end{array}$ & $0.15(0.31)$ & $0.73(1.43)$ & $7.50^{* * *}$ & $2.75^{* *}$ & -0.39 & -0.39 \\
\hline $\begin{array}{l}\text { Annual forest loss before FCI } \\
\text { program, 2004-2010 (\%) }\end{array}$ & $0.31(0.53)$ & $0.59(1.1)$ & $3.37^{* * *}$ & -0.44 & -0.24 & 0.04 \\
\hline Size of parcel (ha) & $64(25)$ & $47(26)$ & $-5.35^{* * *}$ & 0.46 & 0.49 & -0.04 \\
\hline Distance to major town $(\mathrm{km})$ & $4.81(3.37)$ & $3.89(3.03)$ & $-2.07^{* *}$ & 0.88 & 0.21 & -0.12 \\
\hline Distance to major road (km) & $4.13(4.22)$ & $1.77(2.32)$ & $-4.35^{* * *}$ & -0.99 & 0.47 & 0.10 \\
\hline Distance to closest river $(\mathrm{km})$ & $8.43(2.85)$ & $8.17(3.20)$ & -0.67 & 0.16 & 0.05 & 0.07 \\
\hline Distance to closest oil well $(\mathrm{km})$ & $3.90(3.19)$ & $2.61(2.44)$ & $-3.09^{* * *}$ & -0.14 & 0.27 & 0.07 \\
\hline Observations & 63 & 450 & 513 & 112 & 513 & 112 \\
\hline
\end{tabular}

Table 2 Impact of FCI program on reducing deforestation estimated with linear fixed effects panel regression using the matched sample. The number of matched parcels reflects the number of FCI participants matched to non-participant observations in propensity score matching; total observations reflect matched parcels and years of data used in linear fixed effects panel regression. Standard deviations in parentheses. ${ }^{* *} p<0.05 ;{ }^{* * *} p<0.01$.

\begin{tabular}{llll}
\hline \hline & \multicolumn{3}{c}{ Dependent variable: annual deforestation rate } \\
\cline { 2 - 4 } & $\begin{array}{l}\text { 2004-2006 baseline } \\
\text { deforestation used in } \\
\text { match }\end{array}$ & $\begin{array}{l}\text { 2005-2007 baseline } \\
\text { deforestation used in } \\
\text { match }\end{array}$ & $\begin{array}{l}\text { 2006-2008 baseline } \\
\text { deforestation used in } \\
\text { match }\end{array}$ \\
\hline $\begin{array}{l}\text { Estimated average program effect } \\
\text { between 2011-2013 }\end{array}$ & $-0.42^{* * *}(0.14)$ & $-0.45^{* * *}(0.17)$ & $-0.45^{* *}(0.20)$ \\
$\begin{array}{l}\text { Relative impact of FCI on annual } \\
\text { deforestation between }\end{array}$ & $76 \%^{* * *}$ & $73 \%^{* * *}$ & $56 \% 0^{* *}$ \\
$\quad \begin{array}{l}\text { 2011-2013 } \\
\text { Total observations } \\
\text { Matched FCI parcels }\end{array}$ & 784 & 584 & 570 \\
\hline \hline
\end{tabular}

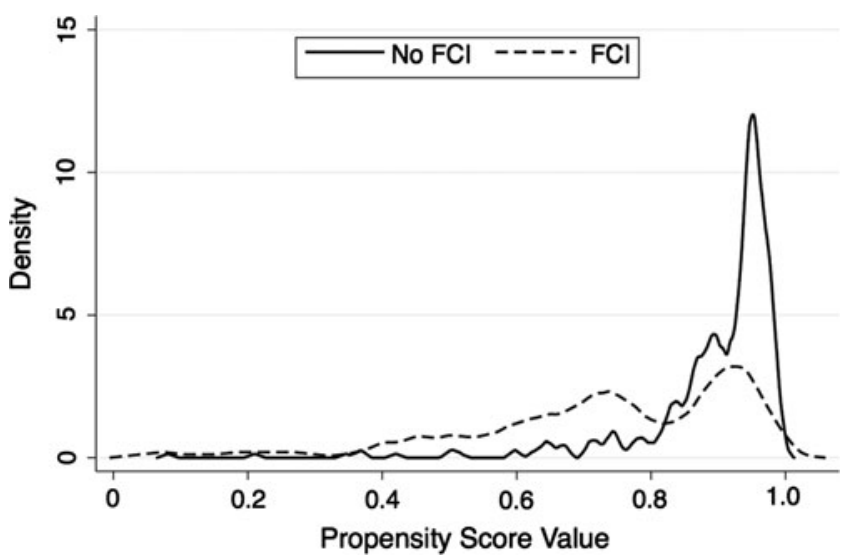

Figure 3 Overlap of propensity score values of parcels enrolled and not enrolled in the FCI program.

the relative reduction in deforestation that can be attributed to the FCI program. This is calculated by dividing the average program effect in Table 2 (Row 1) by the average annual deforestation rate in the matched control observations. Thus, the relative reduction in deforestation that can be attributed to the FCI program ranges between 56 and 76\% (Table 2, Row 2). Since our FCI parcel boundaries included land not enrolled in the program, any substitution slippage is captured by these estimates; if slippage is occurring it would bias down the measured program impacts. Our robustness checks support that the FCI program has a statistically significant impact on lowering deforestation under alternative specifications (Appendix S1).

\section{Focus group interviews}

The 15 communities where focus group interviews were conducted vary in amount of land enrolled in FCIs, from zero to $70 \%$, and in mean annual deforestation rates from close to zero to $1.2 \%$ (Table 3 ). While all community groups had heard of the FCI program and 12 had households enrolled in the program, only eight focus groups had someone present who was enrolled in the program. For the 12 communities with Socio Bosque, smallholders enrolled between 65 and $100 \%$ of their land in the FCI program (Table 3). The main livelihood 
Table 3 Characteristics of communities participating in focus group interviews.

\begin{tabular}{|c|c|c|c|c|c|}
\hline Community & $\begin{array}{l}\text { Number of } \\
\text { titled } \\
\text { households } \\
\text { Number of } \\
\text { hectares }\end{array}$ & $\begin{array}{l}\text { Average annual } \\
\text { deforestation rate for } \\
\text { all titled households } \\
\text { (2004-2013) }\end{array}$ & $\begin{array}{l}\text { Number of } \\
\text { households enrolled } \\
\text { in Socio Bosque } \\
\text { Number of hectares }\end{array}$ & $\begin{array}{l}\text { Average } \\
\text { percentage of } \\
\text { land enrolled in } \\
\text { Socio Bosque }\end{array}$ & $\begin{array}{l}\text { Average annual } \\
\text { Socio Bosque } \\
\text { payment } \\
(U S D)\end{array}$ \\
\hline \multirow[t]{2}{*}{1} & 19 & $0.47 \%$ & 13 & $66 \%$ & $\$ 1200$ \\
\hline & 1148 & & 520 & & \\
\hline \multirow[t]{2}{*}{2} & 19 & $0.26 \%$ & 14 & $92 \%$ & $\$ 1600$ \\
\hline & 1263 & & 769 & & \\
\hline \multirow[t]{2}{*}{3} & 38 & $0.16 \%$ & 6 & $65 \%$ & $\$ 1500$ \\
\hline & 1888 & & 300 & & \\
\hline \multirow[t]{2}{*}{4} & 22 & $0.12 \%$ & 2 & $79 \%$ & $\$ 1600$ \\
\hline & 1242 & & 111 & & \\
\hline \multirow[t]{2}{*}{5} & 18 & $0.92 \%$ & 0 & $0 \%$ & 0 \\
\hline & 819 & & 0 & & \\
\hline \multirow[t]{2}{*}{6} & 24 & $0.91 \%$ & 3 & $78 \%$ & $\$ 1140$ \\
\hline & 1186 & & 114 & & \\
\hline \multirow[t]{2}{*}{7} & 5 & $0.06 \%$ & 3 & $79 \%$ & $\$ 1060$ \\
\hline & 225 & & 158 & & \\
\hline \multirow[t]{2}{*}{8} & 36 & $0.53 \%$ & 2 & $89 \%$ & $\$ 2200$ \\
\hline & 2015 & & 170 & & \\
\hline \multirow[t]{2}{*}{9} & 26 & $1.04 \%$ & 1 & $100 \%$ & $\$ 2500$ \\
\hline & 1046 & & 100 & & \\
\hline \multirow[t]{2}{*}{10} & 39 & $1.02 \%$ & 3 & $84 \%$ & $\$ 1560$ \\
\hline & 2099 & & 158 & & \\
\hline \multirow[t]{2}{*}{11} & 21 & $0.42 \%$ & 0 & $0 \%$ & 0 \\
\hline & 1036 & & 0 & & \\
\hline \multirow[t]{2}{*}{12} & 37 & $0.79 \%$ & 1 & $66 \%$ & $\$ 1500$ \\
\hline & 1499 & & 50 & & \\
\hline \multirow[t]{2}{*}{13} & 32 & $1.21 \%$ & 0 & $0 \%$ & 0 \\
\hline & 1661 & & 0 & & \\
\hline \multirow[t]{2}{*}{14} & 10 & $0.20 \%$ & 1 & $98 \%$ & $\$ 1820$ \\
\hline & 510 & & 66 & & \\
\hline \multirow[t]{2}{*}{15} & 45 & $0.54 \%$ & 2 & $79 \%$ & $\$ 980$ \\
\hline & 1688 & & 68 & & \\
\hline
\end{tabular}

activities of those present were subsistence agriculture; major crops included maize, rice, bananas, coffee and cacao, and most households had pasture for cows. About half of the focus groups mentioned growing coffee, cacao, rice or oil palm as a cash crop, but complained that production quality was low in the area, a direct consequence of aerial fumigation to eradicate coca across the border in Colombia. A few households were employed for short-term work by oil companies, but most reported no off-farm employment. In general, agricultural productivity is lower in this area than reported in nearby regions (Mejia et al. 2015), with little access to markets, and little opportunity for off-farm employment.

When asked whether land use opportunities changed following the acquisition of individual formal titles in 2009, the two responses were (1) no change and (2) the ability to take part in government-sponsored agricultural and forestry programs that required a formal land title. The latter includes FCIs, but two other opportunities mentioned are programs by the Ministry of Agriculture, Livestock, Aquaculture and Fisheries (MAGAP) that provide incentives to plant high quality coffee and fast-growing timber species in this region. Overall, the responses were mixed in terms of actual changes in land use following titling: about half the groups stated no major differences were occurring and the other half mentioned that they were starting to increase agricultural production.

Program participants mentioned three reasons for enrolling in FCIs: the financial incentives, environmental protection and paucity of alternative land uses. Most program participants indicated that the financial incentive was the primary reason for enrollment, with compensation providing an alternative source of income. For instance, one female FCI participant reported 'For me it was welcome, I don't know if it was good for other people, but I like it and since I am poor and old, it gives me some income that I can use when I have an illness or a problem'. Respondents mentioned that the payments are a reliable and steady form of income, in contrast to agricultural and off-farm opportunities; however, many participants complained that the most recent payment was delayed. According to the MAE, this delay was due to 
the fall in global oil prices, which affected the government's financing of the program, and they were working to resolve the situation. Participants mentioned using the incentives for personal expenses, mostly school fees, health care and food. Most participants also mentioned using the money to mark the boundaries of their land, a requirement of the FCI contract. Only one participant mentioned using the economic incentive to invest in off-farm activities, in this case ecotourism.

Beyond economic reasons for enrolling in FCIs, some saw advantage in greater conservation enforcement. Four of the eight focus groups with FCI participants present explicitly mentioned environmental protection as a reason to be involved in the program. Respondents perceived FCIs to be stricter than other conservation regulations. In private conversation after a group meeting, a woman enrolled in an FCI stated her reason for participating as, 'I wanted my neighbour to stop threatening to build a road through my beautiful forest'. In addition to a desire to protect forests, others were concerned about environmental degradation due to oil extraction. In two pre-cooperatives where oil extraction had contaminated local water and land, respondents hoped that FCI lands would be protected from oil drilling.

There was clear indication that lands in FCI contracts were not intensively used before the program: most participants reported that they were only using the land they enrolled to harvest single trees or for subsistence hunting. They also mentioned that the land they enrolled was marshy and unsuitable for agriculture or was remote. In the words of one male program participant, 'There isn't a lot of motivation to expand the agricultural frontier because the land here isn't very good for production'. Nonetheless, in four of the eight focus groups with FCI participants present, when asked what they would do if the program ended, all indicated that without the economic incentives they would have to find ways to make their land productive, or sell the land, which is a new option following the acquisition of formal title.

While the perceived strictness of FCIs attracted some landowners, it discouraged others from participating. A male non-participant commented, 'One can't even walk in Socio Bosque land. It is prohibited'. Considerable anxiety surrounded the liability for protecting enrolled land, as it might create tense relationships between neighbours. Additionally, many non-participants were misinformed about the program. It was unclear to interviewees what happened if the FCI contract was broken and what the liability was if there was a third-party incursion and extraction on their property. Related to these concerns was fear that at the end of the 20-year contracts the forested land would revert to the government. As stated by a male non-participant, 'Some neighbours fear Socio Bosque is a trick, a way for government to take possession of your land'. This fear of expropriation was tied to respondents' general mistrust of the national government.

More than any other response, non-participants explained they did not want to give up access and use rights to their land, especially for such a long period. Most often, they mentioned wanting to retain the ability to harvest the occasional tree, convert some portion to agricultural uses or sell the land in the future. Since the FCI agreement stays with the land if it is sold, similar to a conservation easement, many worried this would reduce their land value. Three focus groups explicitly brought up the liquidity constraints faced with participation, stating that they did not have enough land, or access to other income sources, to set their land aside for 20 years to strict forest conservation. One female non-participant stated, 'Socio Bosque works when you have a large property. In our case, we only have 14 hectares and we have to use it for crops. Although we're interested in Socio Bosque, we can't do it. And look at our neighbour who is in Socio Bosque. She lives on her dad's farm and leaves her farm completely in forest. It is easy for her to be in Socio Bosque'.

\section{DISCUSSION}

\section{Forest conservation incentives as a hybrid form of land governance}

Socio Bosque successfully reduced deforestation on enrolled lands. The change in forest cover in this study area is a result of both a decrease in deforestation on enrolled properties and a large increase in deforestation rates in 2012 and 2013 on un-enrolled properties (Fig. 2 and Appendix S3). Average deforestation rates in Sucumbíos Province were lower than in the study area (average of $0.5 \%$ per year in 2011-2013), but also experienced an increase in deforestation beginning in 2010; thus, the increase observed in this study cannot be linked directly to FCIs or land titling, but is consistent with the overall dynamic nature of deforestation in this region (Holland et al. 2014).

Our interviews help explain why these divergences in deforestation rates between FCI participants and nonparticipants might be occurring. First, formal land titles in the region allowed landowners to enroll in FCIs as well as alternative incentive programs. For some landowners FCIs were an attractive 'investment' and we come back to how this program may have decreased deforestation on participant lands. For titled landowners that did not enroll in FCIs, our interviews suggest that changes in land tenure created opportunities to enroll in MAGAP programs and the security to increase agricultural production. Increased land use changes could occur if titled households cleared land to produce higher value commercial crops, such as coffee, or simply through a continued cycle of expanding the amount of land cleared to meet subsistence needs. While we do not know the exact number of households that enrolled in MAGAP programs or expanded agricultural production after land titling, the increase in deforestation clearly shows that titled non-participants responded to underlying drivers of land use change, whereas FCI participants did not. Given the dynamic nature of deforestation in the region, rates may again fall on titled non-participant lands. Regardless, these divergences illustrate how changes in land tenure act as an indirect driver of land use change, although the specific directions are complex 
and related to the types of opportunities titled landowners have for their land (Robinson et al. 2014).

For FCI participants, one reason they may have lowered deforestation rates even further than their already low rates is because of the financial compensation. This is the intention of FCI programs: to substitute economic values for forest use with economic values for forest conservation. All participants reported that cash incentives were the primary motivation and helped them diversify income sources, in a similar fashion to other findings (Hejnowicz et al. 2014). Many FCI participants were older or had the land available to set aside; for these types of landowners the economic incentive met their opportunity costs and provided the cash needed to pay for basic expenses. We do not have systematic data on use of the economic incentives, nor can we claim that FCIs made participants better off than their neighbours. A common concern with FCIs is that the land set aside would have been conserved anyway (Wunder 2015). In this study area, post-FCI deforestation rates were lower than pre-FCI deforestation for participants (Fig. 2 and Appendix S3). More importantly, however, is what might have happened to participant lands if the FCI program had not existed, given the policy overlap of new land titles. If we had been able to observe the trends in deforestation between FCI participants and similar non-participants in the absence of the FCI program (e.g., Appendix S3), deforestation on the 63 properties currently enrolled in the program might have followed a similar trajectory to those not enrolled. Our interviews also confirm that without this financial opportunity, many FCI landowners would make their land productive or sell the land. Thus, FCIs complement new land titles, providing economic opportunities to 'invest' in forest conservation. Additionally, the overlap of forest restrictions and FCIs provides a complementary, and potentially more equitable, mechanism to achieve forest conservation goals, similar to what has been found elsewhere (Martin et al. 2014).

A second possible reason for a decrease in deforestation on enrolled FCI lands is enforcement. Both participants and non-participants perceived that there were more restrictions on FCI lands than on non-enrolled lands. A few participants recounted enforcement benefits on enrolled lands, telling of instances where they contacted the authorities due to illegal activity, and that the government had responded quickly. Non-participants were cautious of being involved in the program due to the added restrictions and the enforcement role they would have to take on their lands. Additionally, many participants noted that they were using the cash incentives from the FCI program to mark their land, part of fulfilling their conservation contract. Marking boundaries not only signals FCI participation, it underscores an individual's formal land claim. Knowing where property boundaries begin and end, including those of the reserve, is a constant challenge in the study area. Proper demarcation of property may prevent others from mistaking land as unclaimed. These potential added layers of enforcement due to FCIs suggests that the program may complement existing forest restrictions, providing more enforcement than regulatory policies alone (Lambin et al. 2014).

\section{Limitations of forest conservation incentives to reduce deforestation}

With about $7 \%$ of the study area enrolled in Socio Bosque, FCIs will not be a cure-all for deforestation pressures. Similar to other studies, we found that enrollment in FCIs is related to lower opportunity costs and higher conservation motivations (Bremer et al. 2014) and that it is challenging for the poorest of the poor, where opportunity costs are higher due to liquidity and labour constraints, to participate (Pagiola et al. 2005; Jayachandran 2013). In many rural areas, poor farmers depend on trees and their land for emergency expenditures and our focus groups confirmed that loss of access to forest as an economic safety cushion was a main reason for not enrolling. The local scarcity of productive land and lack of access to offfarm employment or credit leaves smallholders all the more reluctant to sign-off forest use for 20 years. Without direct access to credit or allowing complementary activities such as sustainable timber management on enrolled land, it will be difficult for many households to lock their land in strict forest conservation in remote tropical regions (Cranford \& Mourato 2014).

Beyond poverty-related obstacles to participation, we found a consistent lack of willingness to enroll in FCIs across our focus groups. This disinterest was particularly surprising given that by law, landowners must keep $70 \%$ of their land in forest. It is not clear whether better extension and communication would ultimately improve participation given the general lack of trust in the government. Some of this anxiety stems from actual cases of expropriation of non-titled land from individuals living within the reserve. Experiences elsewhere with FCIs have found low willingness to participate when the provider must commit to a long-term contract if there is a lack of trust in the community or implementing agency (Adhikari \& Boag 2013). Without improving these relationships, it is doubtful that many more households will accept economic incentives in exchange for use rights for 20 years. Shorter contracts might work better in situations of low trust, or working through locally respected intermediary organizations might increase participation (Schomers et al. 2015).

\section{CONCLUSION}

The number of FCI programs in the tropics has far outpaced monitoring and evaluation of their outcomes (Samii et al. 2014). As our understanding of FCI programs increases, so do the realities of the opportunities and challenges for this tool to efficiently safeguard forests, let alone improve livelihoods. Thus far, most evaluations have focused on impacts on forest outcomes, but measuring impact can be challenging due to overlap with other policies, and depends on the counterfactual baseline conditions and future land 
use trajectories. In our case, deforestation on non-participant properties was increasing during the same time period as the FCI program, while on FCI properties deforestation was decreasing. While the FCI program was effective at reducing deforestation in our study area, its impacts will likely shift across time depending on the deforestation rates for the non-participant households, as well as the effectiveness of the economic incentives in changing decision-making on participant lands. The land tenure characteristics of our study area, namely the recent acquisition of land title and the overlap with Patrimony Forest, would affect the generalizability of our results. Evaluation of Socio Bosque in other regions of the country, and across individual and communal tenure, is needed to fully assess the national impact of the program.

Our focus group discussions were key for highlighting the dynamic land use change patterns and various economic and social pressures facing landowners in our study region, highlighting the importance of combining counterfactual methods with qualitative information about FCI programs and land use change drivers. Since focus groups are nonrandom, extrapolating our findings to other individuals and communities is not possible. However, many of the opinions expressed in our study echo those found in other studies of Socio Bosque (Bremer et al. 2014). Many FCI programs in the tropics are also interested in achieving poverty alleviation benefits, or at least in providing fair and equitable access for the poor. While we did not conduct a rigorous counterfactual evaluation of FCIs impacts on wellbeing, our focus groups helped shed light on who is participating in the program and why, which has implications for characterizing the social impacts and implications for achieving equity. Finally, our analysis highlights the complex hybridization of land governance in the tropics; FCIs may play an important complementary role to regulatory policies and tenure formalization programs.

\section{ACKNOWLEDGEMENTS}

We thank the communities and individuals that participated in this research for their time and assistance. This research would not have been possible without support from Ecolex staff: Jose Luis Freire, Edmundo Morán and Enrique García. We thank Sam Dupre for field assistance and Mitch Johnson and Tanya Buckingham for cartographic work. M.B. Holland acknowledges funding support from the University of Maryland Baltimore County and L. Naughton-Treves from the University of Wisconsin Graduate School. This manuscript was greatly improved by the suggestions of three anonymous reviewers.

\section{Supplementary material}

To view supplementary material for this article, please visit http://dx.doi.org/10.1017/S0376892916000308

\section{References}

Adhikari, B. \& Boag, G. (2013) Designing payment for ecosystem services schemes: some considerations. Current Opinion in Environmental Sustainability 5: 72-77.

Alix-Garcia, J. M., Shapiro, E. N. \& Sims, K. R. E. (2012) Forest conservation and slippage: evidence from Mexico's national payments for ecosystem services program. Land Economics 88: 613-638.

Bremer, L. L., Farley, K. A. \& Lopez-Carr, D. (2014) What factors influence participation in payment for ecosystem services programs? An evaluation of Ecuador's SocioParamo program. Land Use Policy 36: 122-133.

Cameron, C. A. \& Trivedi, P. K. (2005) Microeconometrics: methods and applications. New York, USA: Cambridge University Press.

Cranford, M. \& Mourato, S. (2014) Credit-based payments for ecosystem services: evidence from a choice experiment in Ecuador. World Development 64: 503-520.

Daniels, A. E., Bagstad, K., Esposito, V., Moulaert, A. \& Rodriguez, C. M. (2010) Understanding the impacts of Costa Rica's PES: are we asking the right questions? Ecological Economics 69: 2116-2126.

de Koning, F., Aguinaga, M., Bravo, M., Chiu, M., Lascano, M., Lozada, T. \& Suarez, L. (2011) Bridging the gap between forest conservation and poverty alleviation: the Ecuadorian Socio Bosque program. Environmental Science and Policy 14: 531-542.

Ferraro, P. J. \& Hanauer, M. M. (2014) Advances in measuring the environmental and social impacts of environmental programs. Annual Reviem of Environment and Resources 39: 485-517.

Guo, S. \& Fraser, M.W. (2010) Propensity score analysis: statistical methods and applications. Washington, D.C., USA; Sage Publications.

Hansen, M. C., Potapov, P. V., Moore, R., Hancher, M., Turubanova, S. A., Tyukavina, A., Thau, D., Stehman, S. V., Goetz, S. J., Loveland, T. R., Kommareddy, A., Egorov, A., Chini, L., Justics, C. O. \& Townshend, J. R. G. (2013) Highresolution global maps of 21 st-century forest cover change. Science 342: 850-853.

Hejnowicz, A. P., Raffaelli, D. G., Rudd, M. A. \& White, P. C. L. (2014) Evaluating the outcomes of payments for ecosystem services programmes using a capital asset framework. Ecosystem Services 9: 83-97.

Holland, M. B., de Koning, F., Morales, M., Naughton-Treves, L., Robinson, B. \& Suárez, L. (2014) Complex tenure and deforestation: implications for conservation incentives in the Ecuadorian Amazon. World Development 55: 21-36.

Imbens, G. W. \& Wooldridge, J. M. (2009) Recent developments in the econometrics of program evaluation. Fournal of Economic Literature 47: 5-86.

Jayachandran, S. (2013) Liquidity constraints and deforestation: the limitations of payments for ecosystem services. The American Economic Reviem 103(3): 309-313.

Jones, K. W. \& Lewis, D. J. (2015) Estimating the counterfactual impact of conservation programs on land cover outcomes: the role of matching and panel regression techniques. PLoS ONE 10: e0141380.

Lambin, E. F., Meyfroidt, P., Rueda, X., Blackman, A., Borner, J., Cerutti, P. O., Dietsch, T., Jungmann, L., Lamarque, P., Lister, J., Walker, N. F. \& Wunder, S. (2014) Effectiveness and synergies of policy instruments for land use governance in tropical regions. Global Environmental Change 28: 129-140. 
Liscow, Z. D. (2013) Do property rights promote investment but cause deforestation? Quasi-experimental evidence from Nicaragua. Fournal of Environmental Economics and Management 65: $241-261$

MAE (2012). Manual Operativo Unificado, Proyecto Socio Bosque, Ministerio del Ambiente [www document]. URL http://sociobosque.ambiente.gob.ec/files/MANUAL\% 20OPERATIVO\%20SB\%20UNIFICADO\%202012.pdf

Martin, A., Gross-Camp, N., Kebede, B. \& McGuire, S. (2014) Measuring effectiveness, efficiency and equity in an experimental payments for ecosystem services trial. Global Environmental Change 28: 216-226.

Mejia, E., Pacheco, P., Muzo, A. \& Torres, B. (2015) Smallholders and timber extraction in the Ecuadorian Amazon: amidst market opportunities and regulatory constraints. International Forestry Reviem 17: 38-50.

Morgan, D. L. \& Krueger, R. A. (1993) When to use focus groups and why. In: Successful Focus Groups: Advancing the State of the Art, ed. D. L. Morgan. Thousand Oaks, CA, USA: Sage.

Pacheco, P., Barry, D., Cronkleton, P. \& Larson, A. (2012) The recognition of forest rights in Latin America: progress and shortcomings of forest tenure reforms. Society $\mathbb{E}$ Natural Resources 25: 556-571.

Pagiola, S., Arcenas, A. \& Platais, G. (2005) Can payments for environmental services help reduce poverty? An exploration of the issues and the evidence to date from Latin America. World Development 33: 237-253.
Programa Socio Bosque (2016) Resumen del Programa Socio Bosque Enero 2016. Quito, Ecuador [www document]. URL http://sociobosque.ambiente.gob.ec/files/Resumen\% 20programa\%20socio\%20bosque\%20enero\%202016.pdf

Robinson, B. E., Holland, M. B. \& Naughton-Treves, L. (2014) Does secure land tenure save forests? A meta-analysis of the relationship between land tenure and tropical deforestation. Global Environmental Change 29: 281-293.

Rubin, D. (2006) Matched sampling for causal effects. New York, USA: Cambridge University Press.

Samii, C., Lisiecki, M., Kulkarni, P. Paler, L. \& Chavis, L. (2014) Effects of payment for environmental services (PES) on deforestation and poverty in low and middle income countries: a systematic review. Campbell Systematic Reviems 11: $1-95$.

Schomers, S., Sattler, C. \& Matzdorf, B. (2015) An analytical framework for assessing the potential of intermediaries to improve the performance of payments for ecosystem services. Land Use Policy 42: 58-70.

Scullion, J. J., Thomas, C. W., Vogt, K. A., Perez-Maqueo, O. \& Logsdon, M. G. (2011) Evaluating the environmental impact of payments for ecosystem services in Coatepec (Mexico) using remote sensing and on-site interviews. Environmental Conservation 38: 426-434.

Wunder, S. (2015) Revisiting the concept of payments for environmental services. Ecological Economics 117: 234243. 